\title{
Proposições de uma investigação com jovens através das midias digitais
}

\author{
Propositions of an investigation with young people throught \\ digital media
}

Ana Carolina Sampaio Zdradek ${ }^{1}$

Dinah Quesada Beck²

\begin{abstract}
Resumo
Este artigo apresenta considerações parciais levantadas a partir de uma pesquisa de mestrado, que tem como objetivo problematizar como as juventudes contemporâneas são educadas pelos artefatos culturais das mídias digitais. Para isso, apresentamos, num primeiro momento, a perspectiva teórica a qual se filia esta investigação, os Estudos Culturais em Educação sob o viés pós-estruturalista. Em um segundo momento, buscamos ressaltar as juventudes contemporâneas enquanto um tempo alargado e plurifacetado. Por fim, discorremos a respeito da netnografia na pesquisa pós-crítica e buscamos ressaltar sua potência para as pesquisas em educação. Finalizamos essa narrativa demonstrando que a partir do estudo dos artefatos culturais é possivel compreender a força da cultura da mídia na composição das identidades juvenis. Marcadores geracionais parecem esmaecidos frente à vivência das juventudes enquanto imperativo construído pela liquidez do tempo contemporâneo. Nesse sentido, o estudo dialoga com a possibilidade de que as juventudes parecem construir suas identidades no transito de universos culturais efêmeros, os quais educam e produzem sentidos na interlocução com as mídias digitais.
\end{abstract}

Palavras-chave: Estudos Culturais. Juventudes. Netnografia

\section{Abstract}

This article presents partial results from an ongoing master's research that aims to problematize how contemporary youths are educated by digital media cultural artifacts. As a starting point, we present Cultural Studies in Education under the post-structuralism bias as this investigation's

\footnotetext{
${ }^{1}$ Graduada em Artes Visuais Licenciatura pela Universidade Federal do Rio Grande - FURG. Mestre em Educação pela Universidade Federal do Rio Grande - FURG. Doutoranda em Educação pela Universidade do Vale do Itajaí (UNIVALI) Associada da Federação de Arte Educadores do Brasil (FAEB). E-mail: anacarolinaestudosculturais@gmail.com

2 Graduada em Pedagogia pela Universidade Federal do Rio Grande - FURG. Mestra em Educação pela Universidade Federal de Pelotas - UFPEL. Doutora em Educação pela Universidade Federal do Rio Grande do Sul - UFRGS. Professora do Instituto de Educação da Universidade Federal do Rio Grande - FURG. Email: dinahqbeck@gmail.com.
}

Interfaces da Educ., Paranaíba, v.10, n.30, p. 7-29, 2019

ISSN 2177-7691 
viewpoint, iterating contemporary youths as a multifaceted and broadened period of time. Then, we discuss netnography in post-critical research, searching for its potential for education research. We conclude by demonstrating that from the study of cultural artifacts it is possible to comprehend the strength from the culture of media in the composition of youthful identities. Generational markers seem dimmed in the face of youthfulness as an imperative built by the liquidity of contemporary time. In this sense, the study dialogues with the possibility that the youths seem to build their identities in the transit of ephemeral cultural universes, which educate and produce meanings in the interlocution with the digital media.

Keywords: Cultural Studies. Youths. Netnograph

\section{As culturas como territórios de pesquisas}

Os Estudos Culturais são um campo de estudos constituído por diferentes tendências epistemológicas e políticas: socialismos, marxismos, estruturalismo, pós-estruturalismo, etc. (VEIGA-NETO, 1996). A concepção dos Estudos Culturais por nós adotada parte da vertente pós-estruturalista, a qual desconfia de muitas criações da modernidade, tais como a linearidade histórica e a noção de progresso. Entendemos que não existe um lugar privilegiado e que sirva de modelo para a produção do conhecimento.

Assim como Dinah Beck e Bianca Guizzo (2013, p. 174) é válido mencionar que "pesquisas abordando a relação estabelecida entre cultura e sociedade, numa perspectiva pós-estruturalista, passaram a ser predominantes dentro da vertente teórica dos Estudos Culturais". Nesse sentido, é primordial compreender que um dos objetivos deste campo é desconstruir práticas naturalizadas, mostrando como a cultura vai sendo socialmente construída e o quanto esta é relacionada com as formas de ser e viver em sociedade. Esta noção é entendida como virada culturalista, pois reconhece o descentramento da consciência e do sujeito, a instabilidade e a provisoriedade dos significados e dos múltiplos arranjos.

De acordo com Maria Lúcia Wortmann, Marisa Costa e Rosa Silveira (2015) ao fazerem uma retrospectiva acerca da emergência e da expansão dos Estudos Culturais no Brasil, pode-se afirmar que foi em meados de 1990 que esta perspectiva se firmou no país. Wortmann, Costa e Silveira (2015, p.

34) propõe a seguinte reflexão:

Interfaces da Educ., Paranaíba, v.10, n.30, p. 7-29, 2019

ISSN 2177-7691 
Mas cabe salientar que é nessa busca pela focalização de questões mais amplas, que parecem residir as principais contribuições que a articulação entre Educação e EC tem possibilitado, na medida em que ela impede que se proceda a uma delimitação definitiva desse campo intermediário, múltiplo ou híbrido de estudos, ou mesmo que se busque centrá-lo obrigatoriamente em uma única e definitiva direção. As análises dos ECE têm se voltado a um anteriormente negligenciado território de pesquisa, que questiona a produtividade da cultura nos processos educativos em curso nas sociedades de hoje.

Fica expressa a atenção dada por este campo aos entre-lugares da cultura, afastando-se das metanarrativas modernas e dos caminhos seguros. É como se uma pedra tivesse sido lançada nas águas da cultura movimentando terrenos e desacomodando o pensamento. Compreendemos como Homi Bhabha (2013, p.20) o conceito de entre-lugares como "terreno para a elaboração de estratégias de subjetivação - singular ou coletiva - que dão início a novos signos de identidade e postos inovadores de colaboração e contestação, no ato de definir a própria ideia de sociedade”.

Kathryn Woodward (2000, p. 09) aborda uma noção muito cara aos Estudos Culturais: a autora nos diz que "a identidade é assim, marcada pela diferença". Uma noção não-essencialista a respeito das questões concernentes a identidade focaliza as diferenças, os olhares se voltam para a maneira com que uma determinada coisa ou os próprios sujeitos mudam com o passar dos séculos. As identidades são mutáveis, sendo assim, relacionais porque são estabelecidas e assinaladas por uma marca simbólica relativamente a outras identidades. Para Tomaz Tadeu da Silva (2000) a identidade e a diferença são inseparáveis, as identidades e as diferenças têm que ser ativamente produzidas. Dessa forma, os Estudos Culturais pósestruturalistas, são como menciona Alfredo Veiga-Neto (2000, p. 48), ao mesmo tempo "um campo de conhecimentos e de militância". É preciso pensar nas identidades para produzirmos diferenças. E como produzir diferenças?

Um currículo e uma pedagogia da diferença deveriam ser capazes de abrir o campo da identidade para estratégias que tendem a colocar 
seu congelamento e sua estabilidade em xeque: hibridismo, nomadismo, travestismo, cruzamento de fronteiras. Estimular, em matéria de identidade, o impensado e o arriscado, o inexplorado e o ambíguo, em vez do consensual e do assegurado, do conhecido e do assentado. Favorecem, enfim, toda experimentação que torne difícil o retorno do eu e do nós ao idêntico (SILVA, 2000, p. 100).

O autor nos mostra que é possivel desestabilizar terrenos construídos artificialmente e desafia-nos a alargar compreensões sobre diversidade, algo já dado e estéril e nos provocando a pensar a diferença, centralmente produtiva porque a diferença é múltipla e se "recusa a se fundir com o idêntico" (SILVA, 2000, p. 101).

Nesse contexto, prosseguimos para longe dos lugares seguros propostos pelo pensamento binário e linear e, em meio aos entre-lugares do novo milênio, tempo em que outras instâncias são percebidas, reconhecidas como pedagógicas, refletidas nos fragmentos do que fora um dia o único espelho da verossimilhança, buscamos nos mover neste artigo. Atualmente são alcançadas outras nuances de representações juvenis pelas multiplicidades que abarcam a nossa cultura contemporânea e, é sobre elas que nos propomos discorrer.

\section{Juventudes contemporâneas: alguém falou em cabeça nas nuvens?}

Pois é recomendável, como nos pedem, determinam e recomendam, que a cabeça esteja na terra, na assim chamada realidade, naquilo a que se referem os jornais e os noticiários de televisão, e não fora daqui, no mundo da lua, flutuando nas nuvens (GANBINI, 2010, p. 150).

Se em algum momento se pensa que os/as jovens da modernidade líquida (BAUMAN, 2001) têm a cabeça nas nuvens, são sonhadores/as e frequentemente tropeçam por serem distraídos/as, pode-se dizer que este entendimento é um tanto quanto equivocado. Talvez os/as jovens estejam mais preocupados/as com "roupas, vestimentas e linguagens" (REGUILLO, 2003, p. 107) e pareçam distraídos/as, mas não merecem esta definição do senso comum. Os tempos na contemporaneidade transcenderam e borraram fronteiras. Atualmente pode ser dito que os/as jovens estão com a cabeça

\footnotetext{
${ }^{3}$ Tradução nossa.

Interfaces da Educ., Paranaiba, v.10, n.30, p. 7-29, 2019
} 
nas nuvens, mas esta nuvem, não quer referir-se à distração e, sim, a um artefato da cultura das midias digitais chamado de nuvem.

$\mathrm{Na}$ sequência desta pesquisa intentamos compreender as dimensões e relações do/a jovem neste tempo veloz e sedutor. Quando alguém pergunta onde vamos guardar determinados arquivos de fotos, vídeos ou outros dados, a resposta que ecoa é: "Vou colocar na nuvem". Sabe que nuvem é esta?

Cloud computing, ou computação em nuvem, é um conceito referente à utilização da memória de armazenamento executada a partir de um lugar na internet (nuvem). A maior característica é dispor de tudo que uma pessoa coloca neste espaço e esta ter acesso em qualquer parte do mundo. Cabe mencionar a empresa Dropbox ${ }^{4}$, em sua página ela apresenta as vantagens dos serviços que oferecem, como a possibilidade de rever lembranças em qualquer lugar e guardar arquivos com segurança, podendo usar qualquer dispositivo próprio ou não.

Pairam na nuvem os signos da cultura, textos, músicas, imagens, mundos virtuais e, nas palavras de André Lemos (2013, p. 15), a nuvem se situa no ciberespaço e nela estão disponiviveis mundos virtuais, simulações e softwares. Isto faz com que os/as usuários/as da nuvem (no caso desta pesquisa os/as jovens) tornem-se ubiquitários, "no momento em que eles estão em algum lugar, eles estão em toda parte - e interconectam-se em um único tecido multicor, fractal, volátil, inflacionista, que é, de toda forma, o metatexto englobante da cultura humana", razão pela qual ilustramos essa afirmação com a descrição escolhida para iniciar esta seção, alguém falou em cabeça nas nuvens? Sabemos que a nuvem não mais significa uma expressão que diminua este/a jovem, mas, sim, remete ao entendimento de um/a jovem que se utiliza da nuvem - cloud, conectado/a aos espaços virtuais e que está com a cabeça cotidianamente nestas nuvens do

\footnotetext{
${ }^{4}$ Dropbox é um serviço para armazenamento e partilha de arquivos. É baseado no conceito de "computação em nuvem". Ele pertence ao Dropbox Inc., sediado em San Francisco, Califórnia, EUA. Disponivel em <https://www.dropbox.com/pt_BR>. Acesso em $10 / 02 / 2016$.
} 
ciberespaço, armazenando sua vida. Elisabete Garbin (2003, p. 120, grifo da autora) faz uma provocação proficua:

Efetivamente, a velocidade com que a mídia eletrônica se transforma está fazendo com que pessoas e discursos estejam em muitos lugares ao mesmo tempo, distâncias sejam abreviadas, imagens e sons circulem vertiginosamente, capitais se reúnam, pessoas se "aproximem" virtualmente e, por que não dizer, realmente?

Pessoas estão trocando arquivos, em contato constante, os arquivos ficam na nuvem, provisoriamente e/ou eternamente. É importante situar estas questões no mote central de compreender como as juventudes do século XXI estão sendo educadas por estes artefatos e como transitam na cultura compartilhando diferentes significados.

Diante deste cenário ubiquitário é importante a contribuição espaçotemporal acerca das juventudes. Segundo Maria Rita Kehl (2004, p. 90), “o prestígio pela juventude no Brasil é recente". Através das palavras da autora podemos começar a desenhar a construção social e histórica do conceito de juventude no Brasil da modernidade sólida. Kehl aborda o pensamento de Nelson Rodrigues, quando este escreveu em uma crônica: “O Brasil de 1920 era uma paisagem de velhos". Isto porque nestes anos:

Um homem de 25 anos já portava o bigode, a roupa escura e o
guarda-chuva necessários para identificá-lo entre os homens de 50 , e
não entre os rapazes de 18 . Homens e mulheres eram mais
valorizados ao ingresso na fase produtiva/reprodutiva da vida do que
quando ainda habitavam o limbo entre infância e a vida adulta
chamado de juventude, ou, como se tornou hábito depois da década
de 1950 , de adolescência (KEHL, 2004, p. 90).

$\mathrm{Na}$ sociedade contemporânea de um mundo líquido moderno (BAUMAN, 2001), algumas racionalidades foram modificadas e, diante disso, conforme aponta a autora, os/as jovens que antes eram púberes e desejavam sair rapidamente do limbo entre infância e fase adulta, passaram a ser entendidos/as como sujeitos integrantes de uma faixa privilegiada das sociedades industriais.

O tempo presente tem sido marcado por ambivalências e nesta redoma encontram-se algumas brechas para entender como os/as jovens passaram a ser considerados/as consumidores lucrativos para as empresas. Kehl analisa que o aumento do período de formação escolar, a colossal disputa Interfaces da Educ., Paranaíba, v.10, n.30, p. 7-29, 2019 
dos mercados de trabalho nos países capitalistas e a recente escassez de empregos destina o/a jovem adulto/a a viver um longo tempo na posição de adolescente, dependente economicamente da família e separado das responsabilidades, sendo assim, inapto para decidir e tomar conta da sua vida.

Em contrapartida, outra noção de jovem passa a ser fabricada. A manutenção da juventude, advinda dos discursos da cultura da mídia começa a ser gestada para sobrepor a antiga fase do limbo, ser encarnada como a melhor fase da vida de um ser humano.

Ser jovem virou slogan, virou clichê publicitário, virou imperativo categórico - condição para se pertencer a uma certa elite atualizada e vitoriosa. Ao mesmo tempo, a "juventude" se revelava um poderosíssimo exercito de consumidores, livres dos freios morais e religiosos que regulavam a relação do corpo com os prazeres e desligados de qualquer discurso tradicional que pudesse fornecer critérios quanto ao valor e à consistência, digamos, existencial de uma enxurrada de mercadorias, tornadas, da noite para o dia, essenciais para a nossa felicidade (KEHL, 2004, p. 92, grifo da autora).

Dessa maneira, é possível compreender algumas interfaces do entendimento destas juventudes plurifacetadas que se moldam continuamente na velocidade fluida das informações que povoam os entrelugares em que drapejam a educação, o trabalho e a cultura.

No século XXI a compreensão de juventude e velhice assumem contornos que outrora seriam inaceitáveis. Parece-nos possivel dizer que, na atualidade, os indivíduos considerados como adultos não mais seguem de modo tão linear como em outrora os padrões de comportamento até então esperados, pois optam por perpetuar um determinado ideário da juventude, o qual alarga seu entendimento. Vivemos um tempo e um espaço em que marcações entre gerações encontram-se esmaecidas de forma a entrecruzarem-se.

A adesão a tecnologias e práticas de consumo, centradas no presente, criam condições para que os mundos infantil e adulto abram-se a interdependências e estabeleçam pontos de contato cada vez mais intensos. Sob tais circunstâncias, crianças e adultos podem consumir as mesmas mercadorias, participar das mesmas atividades e compartilhar preferências, como a atração pela ficção e por formas de entretenimento mediadas eletronicamente (ESPERANÇA, 2013, p. 167).

Interfaces da Educ., Paranaíba, v.10, n.30, p. 7-29, 2019 
Paulo Novaes e Regina Vannuchi (2005, p.10, grifos dos autores) trazem uma intrigante colocação sobre a caracterização deste período considerado privilegiado pela indústria cultural e por sujeitos/as contemporâneos/as.

\begin{abstract}
São arbitrários culturais e regras socialmente construídas que determinam em que momento e por meio de quais rituais de passagem se muda de uma fase de vida para outra. Assim variam as idades cronológicas. $\mathrm{Na}$ concepção das sociedades clássicas grecoromanas, a juventude se referia a uma idade entre os 22 e os 40 anos. Juvenis vem de aeoum, cujo significado etimológico é "aquele que está em plena força de idade". Naquela cultura, a deusa grega Juventa era evocada justamente nas cerimonias do dia em que os mancebos (adolescentes) trocavam a roupa simples pela toga, tornando-se cidadãos de pleno direito.
\end{abstract}

$\mathrm{Na}$ idade antiga a expectativa de vida era curta, era comum a maior parte dos individuos falecerem por volta dos trinta anos, com isto as pessoas passavam de uma etapa da vida praticamente para outra, ou seja, da juventude para a velhice, pois a expectativa de vida era baixa. Ao trazer esta informação destaca-se a similaridade com o fenômeno atual que amplia a noção de juventude. Conforme Kehl (2004, p.89), ao dar-se elasticidade ao conceito, considera-se que no espaço de tempo entre os 18 e 40 anos, "todos os adultos são jovens". Este alargamento não mais tem relação com a expectativa de vida, uma vez que, nos dias atuais, a média de vida paira em torno dos 75,2 anos ${ }^{5}$, hoje, mais do que um intervalo de tempo, as juventudes tornam-se "um estado de espírito, um jeito de corpo, um sinal de saúde e disposição, é um perfil do consumidor, uma fatia do mercado onde todos querem se incluir" (KEHL, 2004, p.89-90).

Os/as habitantes do mundo contemporâneo adotaram um sinônimo menos agressivo para a velhice, a terceira idade, minimizando as características desta fase da vida. A medida em que este termo torna-se naturalizado na cultura um "dano colateral" (BAUMAN, 2013) eleva-se, silenciosamente, o esvaziamento do espaço e tempo do indivíduo até então

\footnotetext{
${ }^{5}$ De acordo com pesquisas realizadas pelo IBGE - Instituto Brasileiro de Geografia e Estatística. Disponivel em: <http://g1.globo.com/ciencia-esaude/noticia/2015/12/expectativa-de-vida-dos-brasileiros-sobe-para-752-anos-dizibge.html> Acesso em 11/02/2016.

Interfaces da Educ., Paranaiba, v.10, n.30, p. 7-29, 2019
} 
considerado adulto. Se a infância permanece considerada a primeira fase da vida e a velhice passa a ser a terceira etapa, o intervalo entre as duas passa a ser ocupado pela noção de juventude que gradativamente derrete a fase adulta, a qual se dilui no ideal de perpetuação do que muitos/as consideram o melhor tempo da vida.

Kehl descreve este fenômeno com a seguinte assertiva: "Passamos de uma longa, longuíssima juventude, direto para a velhice, deixando vazio o lugar que deveria ser ocupado pelo adulto" (2004, p. 90).

A liquidez na contemporaneidade desfaz grande parte dos marcadores entre as fases da vida, mesmo nas sociedades ocidentais sempre existiram ritos de passagem que simbolizavam a prontidão do indivíduo para outro estágio de seu desenvolvimento, não apenas físico, mas emocional e social. Assim, acontecia com os bailes de debutantes que apresentavam a jovem à sociedade e informavam oficialmente que ela estava pronta para assumir responsabilidades da vida adulta, como casar e constituir família. Ao rapaz era o ingresso no serviço militar que o tornava homem, ensinando-lhe o que porventura o contexto familiar não tivesse realizado. Estes dois marcadores da modernidade subsistem no mundo contemporâneo, porém não carregam os mesmos significados. Nem mesmo o término dos estudos ou o ingresso no mercado de trabalho servem como ritos de uma etapa à outra.

Em nossas sociedades laicas, em que faltam ritos de passagem para
sinalizar o ingresso na vida adulta, os objetos de consumo e os
espaços próprios para frequentação adolescente - a lanchonete, o
baile funk, a boate, os megashows, de rua - substituem os ritos
característicos das culturas pré-modernas. Os jovens também
inventam seus próprios ritos. Penso que o consumo de drogas leves
como a maconha ou a cerveja funciona como prova ou desafio para
decidir a entrada dos novatos em certos grupos, estabelecendo a
linha não só entre os caretas e os entendidos, mas entre os que são
vistos como ainda crianças e os que já se consideram com um pé na
vida adulta (KEHL, 2004, p.95, grifos da autora)

A situação descrita pela autora e os novos ritos de passagem criados por aqueles/as que estão ingressando na juventude sinalizam que, embora as fronteiras entre as idades tenham sido enfraquecidas, no que se refere às etapas do desenvolvimento humano, elas permanecem, principalmente no que diz respeito ao amadurecimento emocional do púbere para o adulto. A 
medida em que os/as adultos/as passam a adotar ideais teen, começamos a entender o desamparo vivenciado por estes/as jovens, até então denominados/as como adolescentes que não encontram nos próprios familiares e circuitos sociais que frequentam "adultos" que lhes auxiliem a encontrar perspectivas de futuro e assumir responsabilidades e viver de modo independente. Segundo a mesma autora, "eles buscam encontrar na vida dos mais velhos alguma perspectiva de futuro, mas encontram um espelho deformado de si próprios" (KEHL, 2004, p. 97) e, diante disso, o processo de teenaginação da cultura ocidental está causando a insegurança identitária nos/as jovens situados/as principalmente entre os 13, 15 ou 17 anos de idade, pois perdem gradativamente os referenciais em seus grupos de convivio, fazendo com que busquem por segurança em outras esferas. "Daí a necessidade de identificar-se com comunidades particulares, étnicas, religiosas ou infracionais capazes de recriar um sentimento de inclusão coletiva" (LIPOVETSKY; SERROY, 2011, p.52).

Corroborando para o entendimento das juventudes contemporâneas é importante ressaltar a necessidade de identificação do indivíduo na construção da própria identidade a partir de um processo de "ancoragem comunitária” (LIPOVETSKY; SERROY, 2011, p.52). Aliado a isto, prolifera-se um ideal de busca constante pelo corpo perfeito, um hedonismo característico do século XXI.

\begin{abstract}
Desenvolve-se uma nova relação com o corpo: obsessão com a saúde, culto do esporte, boa forma, magreza, cuidados de beleza, cirurgia estética... manifestações de uma cultura tendencialmente narcísica. Claro que essas lógicas são desenvolvidas de maneira muito desigual em todo o globo, mas por toda parte progridem a dinâmica de individualidade, com a autonomização da existência individual cada vez mais voltada para si mesma, a busca de um bem-estar pessoal e consumidor (LIPOVETSKY; SERROY, 2011, p. 48) [grifos dos autores].
\end{abstract}

A própria noção de felicidade é um paradoxo que transita entre a historicidade moderna que almejava o progresso das ciências e das técnicas e ênfase moderno-líquida que almeja cuidados de beleza e manifesta muitas vezes um culto a si mesmo/a. Os/as jovens contemporâneos/as aprendem desde muito cedo a ocupar alguns lugares no mercado de consumo. 
Toda a publicidade apela para o "sem limites" da vida adolescente representado pela velocidade da moto, pela potência do aparelho de som, pela resistência do carro, pelo barato da cerveja e do cigarro, pelo corpo aeróbico e perfeito malhado nas academias e transformado em ícone sexual, objeto incontestável do desejo de jovens, velhos e crianças. Diante de tanta idealização e na falta de um sistema de referências alternativo aos valores do consumo sistema que deveria estar sendo permanentemente elaborado por jovens e adultos, mas não está - os pais sentem-se desautorizados a barrar certos excessos de seus filhos (KEHL, 2004, p. 100, grifos da autora).

A busca pela segurança torna-se um continuum, tanto para os/as jovens em idade que procuram por modelos que os/as representem, como para os/as que desejam permanecer eternamente jovens e buscam um espelho que lhes mostre o que desejam ver e não as marcas ditadas pelo tempo, transparente nas mudanças corporais naturais ao processo de crescimento, desenvolvimento, envelhecimento e morte.

Um interessante nicho do mercado que nos ajuda a pensar nessas questões referentes ao alargamento da juventude, em especial acerca das práticas estéticas corporais é o da indústria de cosméticos. Conforme Gilles Lipovetsky (2007, p. 116) "na oferta pletórica do mercado: o princípio de autonomia tornou-se a regra de orientação legitima das condutas individuais". O consumidor contemporâneo, de acordo com este autor, ganha a liberdade de fugir aos moldes impostos no passado, ele torna-se um "turboconsumidor", um comprador móvel, que não sente mais necessidade alguma de justificar suas escolhas a quem quer que seja. Deste modo, se alguém gasta a maior parte do seu dinheiro com cosméticos, roupas ou outros adereços, isso apenas diz respeito a si próprio, mesmo que em seu grupo familiar existam outras prioridades.

Neste interim está a nuvem, que passa a assumir lugar de destaque na vida de todos/as, sejam consumidores/as ativos/as ou em estado de latência. Acentua-se a dinâmica da individualidade na modernidade líquida, os canais de acesso a informação multiplicam-se e no Google, que passa a ter tudo que procuramos (ESPERANÇA, 2013).

A nuvem não é física, mas é constituída por um corpo de significados que precisam ser filtrados e não apenas recebidos e armazenados. A nuvem 
traz em si espirais infinitas de informações, notícias e mensagens com ou sem nexo.

Até que fosse estabelecido o processo de formação da nuvem os/as habitantes da contemporaneidade traçavam limites no espaço físico para agrupar seres ou objetos em determinados lugares. Da mesma forma estabeleciam limites em espaços coletivos com a presença de guardas e seguranças. Uma época de autorizações para determinar o que é desejável ou indesejável (BAUMAN, 2011, p. 203); porém no que diz respeito à nuvem, não há um controle externo e, sim, a permissão ou não de cada usuário, de modo completamente individual.

$\mathrm{Na}$ nuvem não há muros ou barreiras se não aqueles erguidos ou derrubados de forma imaterial pelo próprio usuário, que assume ou não suas escolhas de modo plenamente consciente, mas irá colher suas consequências. Nesse sentido, por compreendermos a amplitude do termo juventudes, nos colocamos diante do desafio de propor, metodologicamente ao estudo desenvolvido, uma metodologia inventiva, menos convencional. Entendemos que somos construídos/as na linguagem, nos discursos e pelos diferentes endereçamentos que circundam as relações de poder-saber (SILVA, 2013). Para isso lançamos nossas energias em um território online, e é sobre isso que discorremos a seguir.

\section{Caminhos metodológicos: netnografia em foco}



A autora com a qual abrimos esta seção nos fala acerca da produção dos nossos materiais empíricos na pesquisa qualitativa, nos lembra que é preciso de criatividade e teorizações férteis. Assume que nosso olhar é produtor e intencionado. A partir dessa colocação, interessa-nos apresentar as possibilidades metodológicas que foram criadas para a realização do estudo em desenvolvimento. É importante situar que a pesquisa que está Interfaces da Educ., Paranaíba, v.10, n.30, p. 7-29, 2019 
sendo realizada tem como objetivo problematizar quatro artefatos culturais e seus desdobramentos na vida dos/as jovens contemporâneos/as.

Sendo assim, nosso aparato teórico parte das compreensões e pesquisas desenvolvidas no campo teórico dos Estudos Culturais pósestruturalistas e das metodologias pós-críticas (PARAÍSO, 2014, p. 35), esta compreensão nos permite bricolar, fazer composições. Utilizamo-nos desse entendimento e apontamos que, em nossa pesquisa em andamento não temos uma metodologia una especificamente fechada. "Procedemos em nossas metodologias de modo a cavar/produzir/fabricar a articulação de saberes e a bricolagem de metodologias porque não temos uma única teoria a subsidiar nossos trabalhos". Suscitamos que tivemos como interesse fazer a composição de um grupo com inspiração netnográfica, de modo online, aproveitando o interesse e engajamento que hoje observamos dos/as jovens com os aplicativos móveis digitais. Como nos lançamos neste território online da cibercultura para buscar e convidar os/as integrantes da pesquisa, entendemos que nos utilizaremos de alguns caminhos netnográficos, utilizando os conceitos da etnografia de modo (re)significado. "Uma adaptação metodológica consiste exatamente na observação no ciberespaço, cuja natureza é desterritorializada [...]” (SALES, 2014, p. 119).

Compartilhamos de uma atitude de investigação que pede "responsabilidade, ética, rigor e acima de tudo criatividade e ousadia (SALES, 2014, p. 130). A netnografia consiste em ir ao ambiente virtual viabilizado através dos computadores, celulares, tablets, etc., como pesquisador/a, realizando observações ou até mesmo conversando com as pessoas dos diferentes perfis disponiveis. As linguagens articuladas no ciberespaço contêm características diferenciadas. Segundo Sales (2014, p. 121):

Em termos metodológicos, ao se transitar na fronteira da cibercultura marcada pelo internetês, depara-se com vocabulários, simbolos ou expressões que não são imediatamente reconheciveis. Há linguagens muito específicas de certos grupos culturais dos quais nem sempre o/a pesquisador partilha sentidos. Diante desse 
impasse, por vezes, é necessário solicitar aos membros desses grupos que traduzam aquilo que não se pode compreender.

$\mathrm{Na}$ interface com ciberespaço encontramos muitos recursos e possibilidades, uma linguagem muito utilizada são os emotions, que são os simbolos que traduzem as emoções ou representam um objeto. No caso dos/as usuários/as do WhatsApp provavelmente este modo de expressão seja frequente, pois é característico do grupo cultural que utiliza o aplicativo.

Para a fertilidade dos questionamentos propostos na pesquisa que estamos realizando foi importante que os/as integrantes do grupo tivessem contato com o ambiente virtual e com aplicativos móveis, porém "Se por um lado, a netnografia conta com a vantagem de as informações já virem transcritas, por outro lado, o fato de se ater à linguagem textual redunda na perda da leitura dos gestos e expressões" (SALES, 2014, p. 121). O local da realização da pesquisa está sendo o WhatsApp (aplicativo móvel lotado no celular com acesso também por computadores). A composição do grupo é de 19 integrantes, um número pequeno considerando o limite de pessoas que cabem em um grupo do Whats $A p p^{6}$.

Os/as integrantes foram convidados/as para participar da pesquisa a partir de uma página da rede social Facebook, intitulada Universidade Federal do Rio Grande - FURG, a página é constituída em sua maioria pela comunidade universitária. Como as reuniões aconteceram todas online, não definimos um tempo fechado ou um horário para conversação, até por entender que os/as participantes têm horários diversos. Delimitamos apenas o tempo de duração do grupo no WhatsApp, que foi de duas semanas e, neste intervalo de tempo em que a produção empírica dos dados ocorreu, lançamos/postamos quatro artefatos culturais entendidos como disparadores para suscitar cada discussão.

É importante mencionar que o planejamento dos encontros foi realizado no decorrer dessa pesquisa no levantamento do material elencado como disparador de discussão, material que tem suscitado diálogos entre o

${ }^{6} \mathrm{O}$ limite de pessoas por grupo no aplicativo WhatsApp é de 256 pessoas. Esta informação é do ano de 2016.

Interfaces da Educ., Paranaiba, v.10, n.30, p. 7-29, 2019 
grupo no aplicativo móvel WhatsApp. Sobre a possibilidade de levantar uma discussão a partir de um artefato cultural, Felipe e Guizzo (2004, p. 06, grifos das autoras) corroboram dizendo que existe a "possibilidade de se promover grupos de conversa a partir de artefatos - como propagandas, brinquedos, filmes - que sirvam como "deflagradores" e uma possível discussão no grupo".

Os materiais que escolhemos para atuarem como disparadores de discussão consistem em quatro artefatos culturais das mídias digitais, nos debruçamos sobre estes na próxima seção, a fim de evidenciar algumas análises parciais da pesquisa. Para reforçar uma noção já explicitada anteriormente, é valido dizer que os artefatos culturais das mídias digitais são as produções da cultura em nível digital. O aparelho celular é uma tecnologia, porém as operações e os aplicativos disponíveis nele e a partir dele, são os artefatos culturais das mídias digitais, as músicas, os jogos, aplicativos etc. Estes artefatos/produções culturais foram sendo postados no grupo dos/as jovens no WhatsApp. Esta metodologia se mostra atenta a lugares anteriormente negligenciados, compreende as reconfigurações espaço/temporais que vivemos e procura se valer do território online, enquanto espaço de pesquisa. Compreendemos esta esfera enquanto produtora dos/as jovens, na rede e a partir das produções veiculadas nesta, somos subjetivados/as, de forma com que vamos aprendendo a tomar determinadas posições de sujeito em sociedade.

\section{Ensaios de análise}

A fim de problematizar a escolha dos artefatos culturais postados no grupo para os/as jovens, consideramos importante realizar uma breve análise netnográfica sobre cada um destes.

Figura 1: Jogo Just Dance Now 


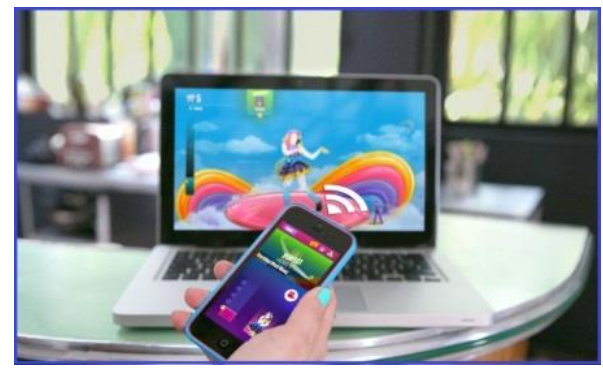

Fonte: Ubisoft 7 .

O Just Dance Now é um jogo digital disponivel como aplicativo móvel, o mesmo foi criado pela empresa Ubisoft e lançado em 25 de setembro de 20148. Este jogo é voltado para quem não possui um videogame, sendo assim a pessoa pode baixá-lo em um smartphone com sistema Android ${ }^{9}$ ou iOS ${ }^{10}$. Para jogar neste aplicativo é preciso de um celular smartphone e um computador, os dois ao mesmo tempo. O celular funciona como controle e as interações acontecem na tela do computador. Este é um jogo de dança em que o/a participante ou os/as participantes entram em uma sala virtual de dança e precisam imitar os movimentos do dançarino virtual sempre segurando o celular em mãos. Cada pessoa na sala virtual corresponde a um indivíduo na frente de um computador dançando as coreografias. Nesse contexto foi possivel analisar, a partir da imersão netnográfica no território online, que os/as jogadores/as possuem um passe "vip" que lhes concede uma quantidade significativa de músicas. Para adquirir mais músicas é necessário investir no jogo, com aquisições por meio de cartão de crédito, exclusivamente.

Os jogos de consumo cada vez mais voláteis e convidativos são armas velozes na luta pela sobrevivência das empresas na modernidade líquida (BAUMAN, 2013). Deste modo, com este disparador foi possivel compreender mais sobre como o consumo vem caracterizando a vida dos/as jovens.

Figura 2: Aplicativo YouCam MakeUp

\footnotetext{
${ }^{7}$ Disponível em: https://www.ubisoft.com/pt-BR/game/just-dance-now/. Acesso em 10/03/2016.

${ }^{8}$ Lançado pela App Store e na Google Play. Disponível em https://pt.wikipedia.org/wiki/Just_Dance_Now

${ }^{9}$ Sitema operacional desenvolvido pela Google.

${ }^{10}$ Sistema operacional móvel da Apple Inc.
}

Interfaces da Educ., Paranaíba, v.10, n.30, p. 7-29, 2019 


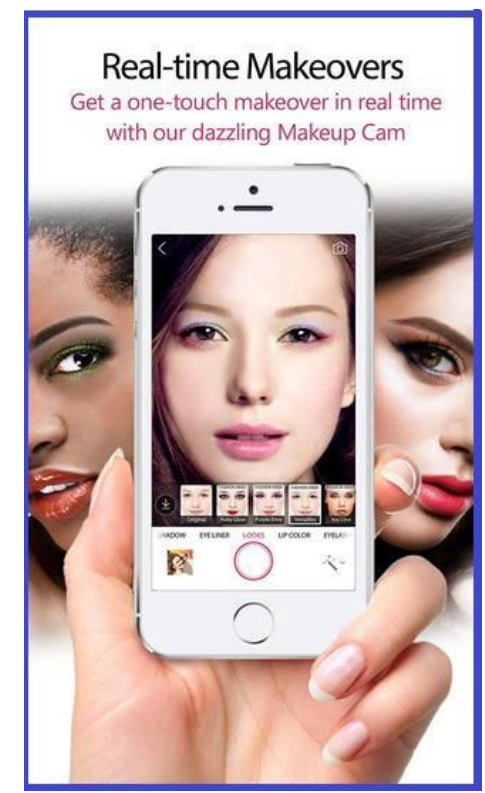

Fonte: Modeliste Magazine ${ }^{11}$

O YouCam MakeUp ${ }^{12}$ consiste em um aplicativo móvel de embelezamento instantâneo, lançado no ano de 2014. Com este artefato cultural buscamos problematizar com os/as jovens algumas questões dos procedimentos dos aplicativos, tendo em vista que nosso grupo foi constituído por aqueles que se sentem vivendo a juventude. Fizemos ao grupo a proposta de experimentar o aplicativo para compreendermos quais efeitos este artefato está produzindo. No decorrer dos diálogos e da experimentação do grupo percebemos que os recursos só funcionavam para corpos que não possuem pelos, isto nos fez compreender que o aplicativo foi pensado apenas para a vivência de algumas pessoas, não contemplando as diferenças dos corpos em sociedade. Outro ponto de análise é a linguagem utilizada nas configurações do aplicativo, sempre no feminino, logo o mesmo pressupõe que apenas mulheres utilizem. Com este disparador de discussão lançamos luzes em questões como o embelezamento e a busca por um corpo plástico, o qual se projeta constantemente nas instâncias digitais.

\section{Figura 3: Imagens do videoclipe}

\footnotetext{
${ }^{11}$ Adaptado de: http://modelistemagazine.com/the-ultimate-beauty-game-changer-youcam-makeup/ Acesso em 08/04/2016

${ }^{12} \mathrm{O}$ nome completo do aplicativo é YouCam MakeUp - Selfie Makeover. Em sua descrição da Google Play menciona que o produto é a melhor câmera de selfie para penteados, maquiagem, e muito mais. Disponível em: https://play.google.com/store/apps/details?id=com.cyberlink.youcammakeup\&hl=pt-br Acesso em 08/04/2016.
} 


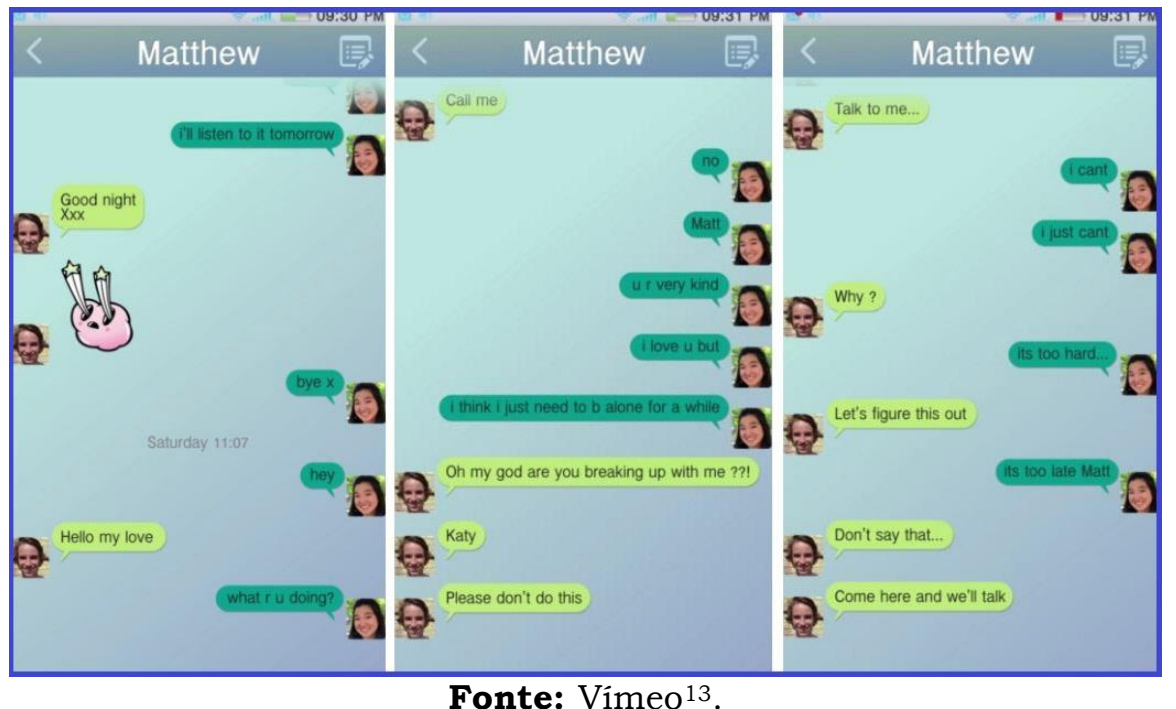

O videoclipe "How Can it Be", cuja tradução significa "Como pode ser", foi um clip produzido em Toronto e lançado no dia cinco de agosto de 2015 no Canadá. Seus criadores são Harrison, Ryan Hemsworth e Star Slinger. O clip compartilha o rompimento de um namoro por mensagem de texto em um aplicativo móvel.

As relações liquidas ou o amor líquido que Bauman problematiza se materializam num relacionamento amedrontado e frágil, numa avidez por incessantes novos começos. Nesse sentido, a internet entra nesse cenário como suavizador dos medos e ansiedades, característicos de nosso tempo. Zygmunt Bauman (2008) defende a ideia de que o fetichismo da mercadoria que assombrava a sociedade de produtores é agora baseado no fetichismo da subjetividade, que aterroriza a sociedade de consumidores, a qual consiste em uma ilusão. Salientamos ainda, que com este artefato não nos centramos na problematização das relações afetivas entre os sujeitos, e sim no modo como se estruturam as relações possibilitadas pelas redes sociais, enfatizando sua arquitetura e estética relacional.

\section{Figura 4: Imagens do videoclipe}

\footnotetext{
${ }^{13}$ Videoclipe da música How Can it Be. Adaptado de: https://vimeo.com/135475344. Acesso em 16/09/2015. Interfaces da Educ., Paranaiba, v.10, n.30, p. 7-29, 2019
} 




Fonte: Youtube ${ }^{14}$.

O quarto e último disparador de discussão foi uma produção experimental desenvolvida por uma professora de sociologia e um grupo de estudantes. A Tchebis Produções, segundo informações encontradas em seu canal no Youtube, constituise uma proposta criada no ano de 2013 por um grupo de estudantes para divulgação das produções audiovisuais relacionadas aos trabalhos solicitados pelos/as professores/as. Divulgado em dezoito de junho de 2015, o documentário feito sobre o WhatsApp e publicado no Youtube se mostrou bastante fértil, por mostrar a utilização do aplicativo de troca de mensagens dentro de uma escola e os/as estudantes no documentário expõe suas opiniões sobre este produto da comunicação. Nesse sentido, o WhatsApp se torna um produtor de identidades juvenis.

Uma prova da influência dessas mudanças na interação humana tem sido as escolhas das palavras do ano. Em 2013, a palavra selfie foi a escolha dos Oxford Dictionaries, o que revela o impacto das tecnologias móveis e a forte presença da fotografia na interação social; em 2014, o Global Language Monitor elegeu, como palavra do ano, o emoji $\vee$ (coração/amor), apesar de não ser uma palavra e, em 2015, o reconhecimento do intenso uso de emojis se reflete na seleção do emoji como palavra do ano dos Oxford Dictionaries (PAIVA, 2016, p. 382, grifos da autora)

A partir destes dados trazidos pela autora é possível problematizar que as juventudes encontram-se subjetivadas pelo dicionário cultural dos emojis, eles invadem as escolas, tornam-se objetos e fazem parte da oralidade.

\footnotetext{
${ }^{14}$ Adaptado de: https://www.youtube.com/watch?v=uWGcViw5TBk. Acesso em 10/03/2016.
} 
Entretanto, estes artefatos educam, subjetivam e produzem modos de ser e viver as juventudes com e na interlocução com as mídias digitais.

Consideramos nesta análise netnográfica (SALES, 2014), feita a partir das produções da cultura em nivvel digital, que o espaço do adulto parece não possuir o status quo de destinatário aos modos de endereçamento (ELLSWORTH, 2011) em exercício nos artefatos culturais das mídias digitais, tendo em vista, conforme os aspectos estudados, que as juventudes e a manutenção destas é que se tornam rentáveis na cultura contemporânea.

\section{Considerações finais}

Neste artigo nos movemos a viajar em entre-lugares, voltamos nossos olhares para compreender e problematizar os/as jovens que dialogam no ciberespaço e se "em geral a tecnologia ultrapassou a política" (BAUMAN, 2014, p. 64) façamos da tecnologia um campo de luta política, uma arena de disputas por significação.

É importante mencionar que esta pesquisa em desenvolvimento não se pretende verificatória, esta não se trata de uma pesquisa de recepção. Procuraremos perceber como os dados produzidos na pesquisa ${ }^{15}$ a partir do grupo no WhatsApp se manifestam e de que formas produzem efeitos, constituem identidades e lançam algumas proposições como: ideais de beleza contemporâneo, a centralidade do crédito na vida dos/as consumidores, as fragilidades das relações e o imperativo da comunicação em rede. Não tentaremos construir uma resposta que explique o que são "realmente" as juventudes na modernidade liquida. Também não é nosso interesse apontar quais dos artefatos culturais das mídias digitais elencados e que se convertem nessa pesquisa como disparadores de discussão são mais ou menos produtores desses/as jovens participantes do grupo. Dizemos isso porque compreendemos que "a própria linguagem com que dizemos o conceito é ambivalente" (WORTMANN e VEIGA-NETO, 2001, p. 27). Nesse sentido, é importante assumir uma humildade epistemológica que compreenda a provisoriedade dos saberes. Desse modo, ficaremos atentas

\footnotetext{
${ }^{15}$ Já realizamos a etapa da coleta produtiva dos dados do grupo de pesquisa no WhatsApp.

Interfaces da Educ., Paranaiba, v.10, n.30, p. 7-29, 2019
} 
aos percursos e aos processos da pesquisa, aos pequenos conflitos, às representações e aos olhares que permitam a produção da multiplicidade de ser jovem na contemporaneidade. Tomaremos os artefatos como fragmentos de um tempo, intenso, no qual a partir destes se dissipam diferentes discursos que trabalham arduamente na construção de quem fomos, quem somos e quem poderemos vir a ser.

As discussões desencadeadas pelos artefatos culturais analisados, como está acontecendo nessa pesquisa, podem ser férteis para a educação contemporânea, pois são problemáticas atentas às reconfigurações da sociedade que vivemos. Entendemos a cultura da mídia enquanto este espaço atuante na composição das identidades jovens. Trabalhar com metodologias pós-criticas é instigante, na medida em que não nos é cobrado fidelidade metodológica, nestas bases não temos filiação disciplinar rígida (NELSON, TREICHELER; GROSSBERG, 2013), são nossos problemas de pesquisa que determinam as posturas assumidas.

\section{Referências bibliográficas}

ALMEIDA, F. Q.; GOMES, I. M.; BRACHT, V. Bauman e a Educação. Belo Horizonte: Autêntica, 2009.

BAUMAN, Zygmunt. Modernidade Líquida. Rio de Janeiro: Zahar, 2001.

- Vida para Consumo: a transformação das pessoas em mercadoria. Rio de Janeiro: Zahar, 2008.

. 44 cartas do Mundo Líquido Moderno. Rio de Janeiro: Zahar, 2011.

- Danos Colaterais: desigualdades sociais numa era global. Rio de Janeiro: Zahar, 2013.

. Cegueira Moral: a perda da sensibilidade na modernidade líquida. Rio de Janeiro: Zahar, 2014.

BHABHA, Homi. O local da cultura. Belo Horizonte, MG: Ed. UFMG, 2013.

BECK, Dinah Quesada; GUIZZO, Bianca Salazar. Estudos Culturais e Estudos de Gênero: proposições e entrelaces às pesquisas educacionais. Holos. Natal, ano 29, vol. 4, p. 172-182, 2013. 
ELLSWORTH, Elizabeth. Modos de endereçamento: uma coisa de cinema; uma coisa de educação também. In: SILVA, Tomaz Tadeu da. (org). Nunca fomos humanos: nos rastros do sujeito. Belo Horizonte: Autêntica, 2001.

ESPERANÇA, Joice Araújo. Ser criança na sociedade de consumidores: outros tempos, outras infâncias. 201f. Tese (Doutorado em Educação Ambiental). Programa de Pós-Graduação em Educação Ambiental, Universidade Federal do Rio Grande, Rio Grande, 2013.

FELIPE, Jane; GUIZZO, Bianca Salazar. Entre batons, esmaltes e fantasias. In: MEYER, Dagmar; SOARES, Rosângela (orgs). Corpo, gênero $e$ sexualidade. Porto Alegre: Mediação, 2004.

GARBIN, Elizabeth Maria. Cultur@s juvenis, identidades e internet. Rev. Bras. Educ. [online]. 2003, n. 23, pp. 119-134, 2003.

GANBINI, Roberto. Com a cabeça nas nuvens. Rev. Pro-Posições [online], Campinas, v. 21, n. 2, pp. 149-159, 2010.

KEHL, Maria Rita. A juventude como sintoma da cultura. In.: NOVAES, Regina; VANNUCHI, Paulo (Orgs). Juventude e Sociedade: Trabalho, Educação, Cultura e Participação. São Paulo, Perseu Abramo, 2004.

LIPOVETSKY, Gilles. A felicidade paradoxal: ensaio sobre a sociedade de hiperconsumo. São Paulo: Companhia das Letras, 2007.

; SERROY, Jean. A cultura mundo: resposta a uma sociedade desorientada. São Paulo: Companhia das Letras, 2011.

LEMOS, André. Cibercultura: tecnologia e vida social na cultura contemporânea. Porto Alegre: Sulina, 2013.

MEYER, Dagmar Estermann; PARAÍSO, Marlucy Alves (Orgs). Metodologias de Pesquisas Pós-Críticas em Educação. Belo Horizonte: Mazza Edições, 2013.

NELSON, Cary; TRICHELER, Paula A; GROSSBERG, Laurence. Estudos culturais: uma introdução. In: SILVA, Tomaz Tadeu da (Org.). Alienígenas na sala de aula: uma introdução aos estudos culturais em educação. Petrópolis: Vozes, 2003.

NOVAES, Regina; VANNUCHI, Paulo (Orgs). Juventude e Sociedade: trabalho, Educação, Cultura e Participação. São Paulo, Perseu Abramo, 2004.

PAIVA, Vera Lúcia Menezes de Oliveira e. A linguagem dos emojis. Trabalhos em Linguística Aplicada. vol.55 no.2 Campinas, mai/ago, 2016. 
PARAÍSO, Marlucy. Metodologias de pesquisas pós-críticas em educação e currículo: trajetórias, pressupostos, procedimentos e estratégias analíticas. In: MEYER, Dagmar Estermann; PARAÍSO, Marlucy Alves (Orgs). Metodologias de Pesquisas Pós-Críticas em Educação. Belo Horizonte, Mazza, 2014.

REGUILLO, Rossana. Las culturas juveniles: um campo de estúdio; breve agenda para la discusión. Rev. Bras. Educ. [online]. 2003, pp. 103-118, 2003.

SALES, Shirley Rezende. Etnografia+netnografia+análise do discurso: articulações metodológicas para pesquisar em Educação. In.: MEYER, Dagmar Estermann; PARAÍSO, Marlucy Alves (Orgs). Metodologias de Pesquisas Pós-Criticas em Educação. Belo Horizonte: Mazza, 2014.

SILVA, Tomaz Tadeu da. Documentos de Identidade: uma introdução às teorias do currículo. Belo Horizonte: Autêntica, 1999.

, Tomaz Tadeu da (Org). Alienígenas na sala de aula: uma introdução aos estudos culturais em educação. Petrópolis, Vozes, 2013.

VEIGA-NETO, Alfredo. A ordem das disciplinas. 344f. Tese (Doutorado em Educação). Programa de Pós-Graduação em Educação, Universidade Federal do Rio Grande do Sul, Porto Alegre, 1996.

Michel Foucault e os Estudos Culturais. In.: COSTA, M. V. (Org.) Estudos Culturas em Educação: mídia, arquitetura brinquedo, biologia, literatura, cinema. Porto Alegre: Ed. Universidade, UFRGS, 2000. pp. 37-72.

Cultura, culturas e educação. Rev. Bras Educ. Rio de Janeiro, n. 23, p. 5-15, 2003.

WODWART, Kathryn. Identidade e diferença: uma introdução teórica e conceitual. In.: SILVA, Tomaz Tadeu da (Org). Identidade e diferença: a perspectiva dos Estudos Culturais. Petrópolis: Vozes, 2000.

WORTMANN, Maria. Lúcia. C; VEIGA-NETO, Alfredo. Estudos culturais da Ciência \& Educação. Belo Horizonte: Autêntica, 2001.

; COSTA, Marisa Vorraber. HESSEL, Rosa Maria. Sobre a emergência e a expansão dos estudos culturais em educação no Brasil. Educação, v. 38, n. 1 , p. 32-48, 2015. 